DOI : 10.47080

\title{
PENGARUH KOMITMEN ORGANISASI DAN KEPUASAN KERJA TERHADAP KINERJA KARYAWAN (BAGIAN PRODUKSI PT. DHARMA POLIMETAL BALARAJA, TANGERANG)
}

\author{
Isrial $^{1}$,M.Ifran Sani' ${ }^{2}$ Sugina $^{3}$ \\ Universitas Raharja Tangerang \\ Universitas Islam Syekh-Yusuf Tangerang \\ Isrialtanjung@gmail.com, Ifran@ raharja.info, Sugina@ raharja.info,
}

\begin{abstract}
Abstrak
Penelitian ini ditujukan untuk menguji pengaruh komitmen organisasi dan kepuasan kerja terhadap kinerja karyawan pada PT. Dharma Polimetal Balaraja, Tangerang. Penelitian ini merupakan penelitian kausal. Populasi penelitian ini adalah karyawan bagian produksi dengan jumlah sampel sebanyak 100 responden. Pemilihan sampel dengan menggunakan teknik probability sampling jenis sampel random sampling. Data dikumpulkan menggunakan metode kuesioner dengan skala ordinal. Alat analisis yang digunakan adalah uji regresi linear berganda yang dijalankan dengan perangkat lunak Statistical Process Social Science (SPSS). Hasil penelitian menujukkan bahwa secara parsial antara komitmen organisasi terhadapkinerja karyawan tidak menunjukan adanya pengaruh yang positif; Sedangkan kepuasan kerja berpengaruh positif terhadap kinerja karyawan, dan adanya pengaruh komitmen organisasi dan kepuasan kerja terhadap kinerja karyawan saecara simultan terdapat pengaruh yang positif.
\end{abstract}

Kata kunci : Komitmen Organisasi, Kepuasan Kerja, dan Kinerja Karyawan. 
JUMANIS - BAJA VOL 4 NO 1 Prodi Kewirausahaan Februari 2022

ISSN : 2686-0554

ESSN : 2686-5939

DOI : $\mathbf{1 0 . 4 7 0 8 0}$

\begin{abstract}
This study aimed to examine the effect of organizational commitment and job satisfaction on employee performance at PT. Dharma Polymetal Balaraja, Tangerang. This research is a causal research. The population of this study were employees of the production division with a total sample of 100 respondents. The sample selection using probability sampling technique, the type of sample is random sampling. Data were collected using a questionnaire method with an ordinal scale. The analytical tool used is multiple linear regression test which is run with Statistical Process Social Science (SPSS) software. The results of the study show that partially between organizational commitment to employee performance does not show a positive influence; While job satisfaction has a positive effect on employee performance, and the influence of organizational commitment and job satisfaction on employee performance simultaneously has a positive effect.
\end{abstract}

Keywords: organizational commitment, job satisfaction, and employee performance.

\title{
1. PENDAHULUAN
}

Dalam rangka merespon dinamika perubahan lingkungan strategis, setiap organisasi dituntut untuk dapat mengelola setiap perubahan yang terjadi secara tepat. Organisasi demikian adalah organisasi yang tumbuh secara dinamis, yang terus menerus dalam proses perubahan, baik untuk memenuhi kebutuhan perkembangan ataupun untuk menghadapi tuntutan perubahan lingkungan strategis, baik intern maupun ekstern organisasi. Hal ini mengakibatkan organisasi berupaya menemukan apa yang menjadi pusat permasalahannya. Salah satu yang coba diangkat dalam permasalahan ini adalah sebuah kepuasan kerja didalam keadaaan ekonomi yang semakin sulit, kita dituntut untuk mencari kepuasan kerja, banyaknya pengangguran dan banyaknya PHK membuat kita kesulitan dalam menemukan tingkat kepuasan hal ini juga menjadi tanggung jawab sebuah organisasi bagaimana agar cara karyawan dapat tercapai kepuasan kerjanya.

Kepuasan kerja juga menjadi peran penting dalam perusahaan. Kepuasan merupakan keadaan emosional, dimana terjadi ataupun tidak terjadi titik temu antara nilai balas 
JUMANIS - BAJA VOL 4 NO 1 Prodi Kewirausahaan Februari 2022

ISSN : 2686-0554

ESSN : 2686-5939

DOI : $\mathbf{1 0 . 4 7 0 8 0}$

jasa kerja dari perusahaan atau organisasi dengan tingkat nilai balas jasa yang diinginkan oleh karyawan yang bersangkutan.

Kinerja karyawan dalam suatu perusahaan sangatlah penting karena apabila kinerja karyawannnya kurang baik, maka dapat dipastikan perusahaan tidak mampu bersaing dengan perusahaan lain. Dengan kinerja karyawan yang baik diharapkan perusahaan akan mampu bersaing dengan perusahaan lain.

Wibowo (2010) mendefinisikan pengertian manajemen kinerja dengan mengacu pada pendapat Armstrong (2004:9) bahwa manajemen kinerja adalah sebagai sarana untuk mendapatkan hasil yang lebih baik dari organisasi, tim, dan individu dengan cara memahami dan mengelola kinerja dalam suatu kerangka tujuan, standar, dan persyaratan -persyaratan atribut yang disepakati.

Berdasarkan latar belakang yang telah di uraikan di atas, maka penelitian ini di beri judul "Pengaruh Komitmen Organisasi dan Kepuasan Kerja Terhadap Kinerja Karyawan (Bagian Produksi PT. Dharma Polimetal Balaraja - Tangerang)”.

\section{Perumusan Masalah}

Berdasarkan uraian latar belakang diatas, maka perumusan masalah dari penenlitian ini adalah;

1. Apakah Komitmen Organisasi dan Kepuasan Kerja berpengaruh terhadap Kinerja Karyawan secara parsial?

2. Bagaimana cara mengetahui komitmen organisasi dan kepuasan kerja berpengaruh terhadap karyawan secara simultan?

\section{Tujuan Penelitian}

1. Untuk mengetahui pengaruh Komitmen Organisasi, dan Kepuasan Kerja, berpengaruh terhadap Kinerja Karyawan PT. Dharma Polimetal secara parsial.

2. Untuk mengetahui pengaruh Komitmen Organisasi, dan Kinerja Karyawan terhadap Kepuasan Kerja pada karyawan PT. Dharma Polimetal bagian produksi secara simultan. 
ISSN : 2686-0554

ESSN : 2686-5939

DOI : 10.47080

\section{KAJIAN TEORI}

\section{Komitmen Organisasi}

(Meyer dan Allen, 1991 dalam Karina 2009) merumuskan suatu definisi mengenai komitmen organisasi sebagai suatu konstruk psikologis yang merupakan karakteristik hubungan anggota organisasi dengan organisasinya dan memiliki implikasi terhadap keputusan individu untuk melanjutkan keanggotaannya dalam berorganisasi.

\section{Kinerja Karyawan}

Wibowo (2010) mengemukakan pendapat Armstrong (2004:29) lebih melihat manajemen kinerja sebagai sarana untuk mendapatkan hasil yang lebih baik dari organisasi, tim, dan individu dengan cara memahami dan mengelola kinerja dalam suatu kerangka tujuan, standar, dan persyaratan-persyaratan atribut yang disepakati.

\section{Kepuasan Kerja}

Wibowo (2010) mendefinisikan Kepuasan kerja dengan mengacu pada pendapat (Robbins,2003:78) adalah sikap umum terhadap pekerjaan seseorang, yang menunjukan perbedaan antara jumlah penghargaan, yang diterima pekerja dan jumlah yang mereka yakini seharusnya mereka terima

\section{METODE PENELITIAN}

\section{Obyek Penelitian}

\section{Lokasi Penelitian}

Untuk mendapatkan informasi dan data yang diperlukan dalam penyusunan penelitian ini, maka penulis memilih PT. Dharma Polimetal sebagai lokasi penelitian. yang dimana informasi dan data tersebut dikhususkan pada Karyawan bagian produksi PT. Dharma Polimetal. Penelitian ini akan dilakukan pada Karyawan bagian produksi PT. Dharma Polimetal yang ada di daerah Balaraja - Tangerang. 
JUMANIS - BAJA VOL 4 NO 1 Prodi Kewirausahaan Februari 2022

ISSN : 2686-0554

ESSN : 2686-5939

DOI : $\mathbf{1 0 . 4 7 0 8 0}$

\section{Populasi}

Populasi adalah wilayah generalisasi yang terdiri atas; obyek/subyek yang mempunyai kualitas dan karakteristik tertentu yang ditetapkan oleh peneliti untuk dipelajari dan kemudian ditarik kesimpulannya (sugiyono, 2012:80).

Dalam penelitian ini yang menjadi populasi adalah karyawan produksi PT. Dharma Polimetal Balaraja Tangerang sebanyak 1500. Dapat dilahat pada gambar 3.2 sebagai berikut:

\section{Gambar 3.2}

\begin{tabular}{|c|c|c|}
\hline Shift & Pukul & Jumlah Karyawan Produksi \\
\hline 1 & $23.00-07.00$ & 500 \\
\hline 2 & $08.00-16.00$ & 500 \\
\hline 3 & $17.00-23.00$ & 500 \\
\hline \multicolumn{2}{|c|}{ Total } & 1500 \\
\hline
\end{tabular}

Sumber: CV. Periyangan (Katring)

\section{Sampel}

Sugiyono (2012:81) mendefinisikan sampel adalah bagian dari jumlah dan karakteristik yang dimiliki oleh populasi tersebut. Bila populasi besar, dan peneliti tidak mungkin mempelajari semua yang ada pada populasi, misalnya karena keterbatasan dana, tenaga dan waktu, maka peneliti dapat menggunakan sampel yang diambil dari populasi itu. Apa yang dipelajari dari sampel itu, kesimpulannya akan dapat diberlakukan untuk populasi. Untuk itu sampel yang diambil dari populasi harus betul-betul representatif (mewakili).

\section{Metode Pengumpulan Data}

\section{Data Primer}

Istijanto (2009) mendefinisikan data primer data asli yang dikumpulkan oleh periset untuk menjawab masalah risetnya secara khusus. Dalam hal ini, penelitian terhadap karyawan produksi PT. Dharma Polimetal Balaraja, Tangerang. Sebagai obyek penelitian dan responden.

1) Kuesioner (angket) 
JUMANIS - BAJA VOL 4 NO 1 Prodi Kewirausahaan Februari 2022

ISSN : 2686-0554

ESSN : 2686-5939

DOI : $\mathbf{1 0 . 4 7 0 8 0}$

Data dikumpulkan menggunakan metode kuesioner (angket) berdasarkan pertanyaan kepada para konsumen. Metode kuesioner merupakan teknik pengumpulan data yang dilakukan dengan cara memberi seperangkat pertanyaan atau pertanyaan tertulis kepada responden untuk menjawabnya.

\section{Analisis Uji Validitas dan Realiabilitas}

\section{Uji Validitas}

Sugiyono (2012:267) mengatakan bahwa validitas merupakan derajat ketepatan antara data yang terjadi pada objek penelitian dengan daya yang dapat dilaporkan oleh peneliti. Dengan demikian data yang valid adalah data "yang tidak berbeda" antara data yang dilaporkan oleh peneliti dengan data yang sesungguhnya terjadi pada obyek penelitian.

\section{Uji Reliabilitas}

Susan Stainback dalam Sugiyono (2012:267) menyatakan bahwa reliabilitas berkenaan dengan derajat konsistensi dan stabilitas data atau temuan. Dalam pandangan positivistik (kuantitatif), suatu data dinyatakan reliabel apabila dua atau lebih penelitian dalam obyek yang sama menghasilkan data yang sama, atau peneliti dalam waktu berbeda menghasilkan data yang sama, atau sekelompok data bila dipecah menjadi dua menunjukkan data yang tidak berbeda.

\section{ANALISIS HASIL PEMBAHASAN}

Penulis telah melakukan penelitian mengenai pengaruh komitmen organisasi dan kepuasan kerja terhadap kinerja karyawan PT. Dharma Polimetal Blaraja Tangerang dengan menyebarkan 100 kuesioner yang masing-masing terdiri dari 15 pertanyaan. Dalam penelitian ini dilakukan penyebaran kuesioner kepada karyawan produksi.

\section{Uji Validitas}

Uji signifikansi dilakukan dengan dasar pengambilan keputusan:

1) Jika p-value $<\alpha(0,05)$ maka dikatakan tidak valid.

2) Jika p-value $>\alpha(0,05)$ maka dikatakan valid. 
JUMANIS - BAJA VOL 4 NO 1 Prodi Kewirausahaan Februari 2022

ISSN : 2686-0554

ESSN : 2686-5939

DOI : $\mathbf{1 0 . 4 7 0 8 0}$

Tabel 4.5

Hasil Analisis Uji Validitas Komitmen Organisasi(X1)

\begin{tabular}{|l|l|l|l|}
\hline \multirow{3}{*}{ iabel } & Pertanyaan & Nilai & Hasil \\
\hline \multirow{5}{*}{ X1 } & KO1 & 0,591 & Valid \\
\cline { 2 - 4 } & KO2 & 0,683 & Valid \\
\cline { 2 - 4 } & KO3 & 0,725 & Valid \\
\cline { 2 - 4 } & KO4 & 0,567 & Valid \\
\cline { 2 - 4 } & KO5 & 0,638 & Valid \\
\hline
\end{tabular}

Sumber: Data Diolah Menggunakan SPSS 18

Tabel 4.6

Hasil Analisis Uji Validitas Kepuasan Kerja (X2)

\begin{tabular}{|l|l|l|l|}
\hline Variabel & Pertanyaan & Nilai & Hasil \\
\hline \multirow{4}{*}{$\mathbf{X 2}$} & KPK1 & 0,680 & Valid \\
\cline { 2 - 4 } & KPK2 & 0,659 & Valid \\
\cline { 2 - 4 } & KPK3 & 0,638 & Valid \\
\cline { 2 - 4 } & KPK4 & 0,488 & Valid \\
\cline { 2 - 4 } & KPK5 & 0,655 & Valid \\
\cline { 2 - 4 } & KPK6 & 0,490 & Valid \\
\hline
\end{tabular}

Sumber: Data Diolah Menggunakan SPSS 18

Bedasarkan tabel diatas maka dapat di bandingkan antara pearson correlation dengan nilai kritis pada taraf signifikan yaitu 0,05. Maka dapat disimpulkan bahwa semua kuesioner valid karena nilai Pearson Correlation semuanya lebih dari taraf signifikan >0,05.

Bedasarkan tabel diatas maka dapat di bandingkan antara pearson correlation dengan nilai kritis pada taraf signifikan yaitu 0,05. Maka dapat disimpulkan bahwa semua kuesioner valid karena nilai Pearson Correlation semuanya lebih dari taraf signifikan >0,05. 
JUMANIS - BAJA VOL 4 NO 1 Prodi Kewirausahaan Februari 2022

ISSN : 2686-0554

ESSN : 2686-5939

DOI : 10.47080

Tabel 4.7

Hasil Analisis Uji Validitas Kinerja Karyawan (Y)

\begin{tabular}{|l|l|l|l|}
\hline Variabel & Pertanyaan & Nilai & Hasil \\
\hline \multirow{4}{*}{ Y } & KK1 & 0,344 & Valid \\
\cline { 2 - 4 } & KK2 & 0,669 & Valid \\
\cline { 2 - 4 } & KK3 & 0,743 & Valid \\
\cline { 2 - 4 } & KK4 & 0,661 & Valid \\
\hline
\end{tabular}

Sumber: Data Diolah Menggunakan SPSS 18

Bedasarkan tabel diatas maka dapat di bandingkan antara pearson correlation dengan nilai kritis pada taraf signifikan yaitu 0,05. Maka dapat disimpulkan bahwa semua kuesioner valid karena nilai Pearson Correlation semuanya $>0,05$.

\section{Uji Reliabilitas}

Tabel 4.8 Hasil Uji Relibialitas Komitmen Oragnisasi

Reliability Statistics

\begin{tabular}{|l|l|}
\hline Cronbach's Alpha & N of Items \\
\hline, 639 & 5 \\
\hline
\end{tabular}

Sumber: Data Diolah Menggunakan SPSS 18

Bedasarkan tabel diatas maka dapat disimpulkan bahwa diketahui nilai Cronbach's Alpha adalah sebesar 0,639. Karena nilai Cronbach's Alpha 0,639 lebih dari 0,6 maka dapat disimpulkan bahwa hasilnya adalah reliable.

Tabel 4.9 Hasil Uji Relibialitas Kinerja karyawan

Reliability Statistics

\begin{tabular}{|l|l|}
\hline $\begin{array}{l}\text { Cronbach's } \\
\text { Alpha }\end{array}$ & $\begin{array}{l}\mathrm{N} \text { of } \\
\text { Items }\end{array}$ \\
\hline, 628 & 4 \\
\hline
\end{tabular}

Sumber: Data Diolah Menggunakan SPSS 18 
JUMANIS - BAJA VOL 4 NO 1 Prodi Kewirausahaan Februari 2022

ISSN : 2686-0554

ESSN : 2686-5939

DOI : 10.47080

Bedasarkan tabel diatas maka dapat disimpulkan bahwa diketahui nilai Cronbach's Alpha adalah sebesar 0,628. Karena nilai Cronbach's Alpha 0,628 lebih dari 0,6 maka dapat disimpulkan bahwa hasilnya adalah reliable.

Tabel 4.10 Hasil Uji Relibialitas Kepuasan Kerja

Reliability Statistics

\begin{tabular}{|l|l|}
\hline $\begin{array}{l}\text { Cronbach's } \\
\text { Alpha }\end{array}$ & $\begin{array}{l}\mathrm{N} \text { of } \\
\text { Items }\end{array}$ \\
\hline, 651 & 6 \\
\hline
\end{tabular}

Sumber: Data Diolah Menggunakan SPSS 18

Bedasarkan tabel diatas maka dapat disimpulkan bahwa diketahui nilai Cronbach's Alpha adalah sebesar 0,651. Karena nilai Cronbach's Alpha 0,651 lebih dari 0,6 maka dapat disimpulkan bahwa hasilnya adalah reliable.

\section{Uji Asumsi Klasik}

\section{a. Uji Autokolerasi}

Uji autokorelasi bertujuan untuk menguji apakah dalam regresi linear ada korelasi antara kesalahan pengganggu pada periode $t$ dengan kesalahan pengganggu pada periode t-1. Autokorelasi muncul karena observasi yang berurutan sepanjang waktu berkaitan satu sama lainnya. Untuk mendeteksi ada tidaknya autokorelasi dapat dilakukan dengan Uji Durbin Watson. Model regresi terbebas dari gejala autokorelasi jika terletak di daerah no autocorrelation. Hasil olah data SPSS dapat dilihat pada tabel dibawah ini :

Tabel 4.29 Model Summary

\begin{tabular}{|l|l|}
\hline Model & Durbin-Watson \\
\hline 1 & 1,668 \\
\hline
\end{tabular}

a. Predictors: (Constant), KEPUASAN KERJA, KOMITMEN ORGANISASI 
JUMANIS - BAJA VOL 4 NO 1 Prodi Kewirausahaan Februari 2022

ISSN : 2686-0554

ESSN : 2686-5939

DOI : 10.47080

b. Dependent Variable: KINERJA KARYAWAN

Sumber: Hasil data yang diolah dengan SPSS 18

Berdasarkan tabel di atas dapat dilihat dari ketentuan pengambilan keputusan Durbin Watson, apabila (d) berada di antara 1,537 - 2,463 maka tidak ada autokorelasi. Dari hasil data diatas bahwa nilai Durbin-Watson yaitu 1,668 terletak antara 1,537 - 2,463 berarti tidak ada autokorelasi.

b. Uji Heteroskedastisitas

\section{Gambar 4.1}

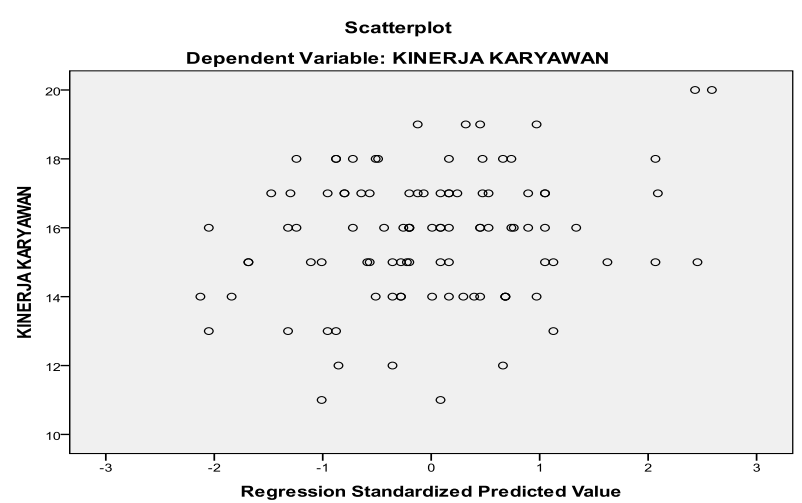

Sumber : Hasil Diolah dengan SPSS 18

Dari grafik tersebut terlihat titik-titik yang menyebar secara acak, tidak membentuk suatu pola tertentu yang jelas, serta tersebar baik di atas maupun dibawah angka 0 (nol) pada sumbu $\mathrm{Y}$, hal ini berarti tidak terjadi penyimpangan asumsi klasik heterokedastisitas pada model regresi yang dibuat, dengan kata lain menerima hipotesis homoskedastisitas.

\section{UJI HIPOTESIS}

a. Uji t Parsial

Tabel 4.32

(Hasil Uji Anova)

Coefficients $^{\mathrm{a}}$

\begin{tabular}{|c|c|c|c|c|c|c|}
\hline \multirow{2}{*}{\multicolumn{2}{|c|}{ Model }} & \multicolumn{2}{|c|}{$\begin{array}{l}\text { Unstandardized } \\
\text { Coefficients }\end{array}$} & \multirow{2}{*}{\begin{tabular}{|l|} 
Standardize \\
d \\
Coefficient \\
s \\
Beta \\
\end{tabular}} & \multirow[t]{2}{*}{$\mathrm{T}$} & \multirow[t]{2}{*}{ Sig. } \\
\hline & & B & Std. Error & & & \\
\hline 1 & (Constant) & 11,802 & 2,213 & & 5,334 &, 000 \\
\hline
\end{tabular}


JUMANIS - BAJA VOL 4 NO 1 Prodi Kewirausahaan Februari 2022

ISSN : 2686-0554

ESSN : 2686-5939

DOI : 10.47080

\begin{tabular}{|l|l|l|l|l|l|l|}
\hline \multirow{2}{*}{$\begin{array}{l}\text { KOMITMEN } \\
\text { ORGANISASI }\end{array}$} &,- 034 &, 084 &,- 042 &,- 409 &, 683 \\
\cline { 2 - 7 } & KEPUASAN KERJA & 196 &, 082 &, 244 & 2,385 &, 019 \\
\hline
\end{tabular}

Sumber: Hasil data yang diolah dengan SPSS $1 I$

Diterima atau ditolaknya hipotesis, maka dilakukan uji signifikan satu pihak yaitu pihak kanan dengan hipotesis sebagai berikut:

\section{Hipotesis:}

Ho : Secara parsial tidak ada pengaruh signifikan antara Komitmen Organisasi Kinerja Karyawan.

Ha : Secara parsial ada pengaruh signifikan antara Komitmen Organisasi terhadap Kinerja Karyawan.

Dari tabel 4.26 secara parsial dapat dijelaskan pengaruh antara variabel komitmen organisasi $\left(\mathrm{X}_{1}\right)$ terhadap kinerja karyawan $(\mathrm{Y})$, didapat nilai $\mathrm{T}$ sebesar -0,409 dengan probabilitas 0,683. Dengan demikian hipotesis Ho diterima dan Ha ditolak. Di lain pihak komitmen organisasi tidak mempengaruhi kinerja karyawan secara parsial.

\section{Hipotesis:}

Ho : Secara parsial tidak ada pengaruh signifikan antara kepuasan kerja terhadap kinerja karyawan.

Ha : Secara parsial ada pengaruh signifikan antara kepuasan kerja terhadap kinerja karyawan.

Dari tabel 4.26 secara parsial dapat dijelaskan pengaruh antara variabel kepuasan kerja $\left(\mathrm{X}_{2}\right)$ terhadap kinerja karyawan $(\mathrm{Y})$, didapat nilai $\mathrm{T}$ sebesar untuk 2,385 dengan probabilitas 0,019. Dengan demikian hipotesis Ho ditolak dan Ha diterima. Maka kepuasan kerja mempengaruhi kinerja karyawan secara parsial.

Persamaan umum regresi linear berganda adalah :

$$
\begin{aligned}
& Y=a+b_{1} \cdot x_{1}+b_{2} \cdot x_{2} \\
& Y=11,229-0,14 X_{1}+0,247 X_{2}
\end{aligned}
$$

Keterangan :

$\mathrm{Y}=$ Kinerja Karyawan

$\mathrm{X} 1=$ Komitmen Organisasi 
JUMANIS - BAJA VOL 4 NO 1 Prodi Kewirausahaan Februari 2022

ISSN : 2686-0554

ESSN : 2686-5939

DOI : 10.47080

$\mathrm{X} 2=$ Kepuasan Kerja

$\mathrm{b}_{1} \quad=$ Koefisien Regresi omitmen Organisasi

$\mathrm{b}_{2} \quad=$ Koefisien Regresi Kepuasan Kerja

Tabel 4.33

(Hasil Uji F)

ANOVAb

\begin{tabular}{|ll|l|l|l|l|l|}
\hline Model & $\begin{array}{l}\text { Sum of } \\
\text { Squares }\end{array}$ & Df & $\begin{array}{l}\text { Mean } \\
\text { Square }\end{array}$ & F & Sig. \\
\hline $\begin{array}{llllll}\text { 1 } \\
\text { n } \\
\end{array}$ & 19,383 & 2 & 9,692 & 2,868 &, $062^{\text {a }}$ \\
& Residual & 327,777 & 97 & 3,379 & & \\
& Total & 347,160 & 99 & & & \\
\end{tabular}

a. Predictors: (Constant), KEPUASAN KERJA, KOMITMEN

ORGANISASI

b. Dependent Variable: KINERJA KARYAWAN

Sumber: Data Diolah Menggunakan SPSS 18

\section{Kesimpulan}

Penelitian ini dimaksudkan untuk mengetahui apakah komitmen organisasi dan kepuasan kerja berpengaruh terhadap kinerja karyawan PT. Dharma Polimetal Balaraj Tangerang. Berdasarkan data yang terkumpul dan dilakukan analisis dengan menggunakan pengujian secara statistik antara lain : Uji Validitas dan Reliabilitas, sedangkan Uji hipotesis dilakukan dengan menggunakan regresi linier berganda, maka dapat diambil kesimpulan sebagai berikut:

1. Terdapat pengaruh secara bersama-sama antara komitmen organisasi dan kepuasan kerja terhadap kinerja karyawan.

2. Terdapat pengaruh secara signifikan antara kepuasan kerja yang dilakukan PT. Dharma Polimetal terhadap kinerja karyawan.

3. Tidak ada pengaruh secara signifikan antara komitmen organisasi yang dilakukan PT. Dharma Polimetal terhadap kinerja karyawan. 
JUMANIS - BAJA VOL 4 NO 1 Prodi Kewirausahaan Februari 2022

ISSN : 2686-0554

ESSN : 2686-5939

DOI : 10.47080

\section{Saran}

Bagi PT. Dharma Polimetal Balaraja Tangerang :

1. Untuk meningkatkan kinerja karyawan. PT. Dharma Polimetal harus lebih meningkatkan kepuasan kerja dengan cara memberi suasana kenyamanan agar karyawan produksi merasa nyaman bila berada pabrik

\section{DAFTAR PUSTAKA}

Arikunto, S. 2010. Prosedur Penelitian Suatu Pendekatan Praktik. Jakarta: PT Rineka Cipta.

Ghozali, Imam. (2005). Aplikasi Analisis Multivariat Dengan Program SPSS, Cetakan Keempat. Semarang: Badan Penerbit Universitas Diponogoro.

Hariandja, Marihot Tua Edendi, 2002, Manajemen Sumber Daya Manusia, Grasindo Jakarta.

Hasibuan, Malayu S.P,(2008), Manajemen sumber Daya Manusia (Edisi Revisi), Penerbit Bumi Aksara Jakarta.

Karina. 2009. Komitmen Organisasi, 17-11-2009, http://rumahbelajarpsikologi.com.

Mangkunergara, Anwar Prabu. 2006. Evaluasi Kinerja Sumber Daya Manusia. Bandung: Rafiak Aditama.

Marwansyah. 2010. Manajemen Sumber Daya Mnausia, Edisi Kedua. Bandung: Alfabeta.

Prawirosentono, Suryadi. 2008. Kebijakan Kinerja Karyawan. Yogyakarta: BPFE.

Priyatno, Duwi. (2010). Teknik Mudah dan Cepat Melakukan Analisis Data Penelitian dengan SPSS. Yogyakarta: Gava Media.

Sugiyono. 2012. Metodologi Penelitian Kuantitatif Kualitatif dan R\&D. Bandung: ALFABETA. 
JUMANIS - BAJA VOL 4 NO 1 Prodi Kewirausahaan Februari 2022

ISSN : 2686-0554

ESSN : 2686-5939

DOI : $\mathbf{1 0 . 4 7 0 8 0}$

Triton PB. 2009. Mengelola Sumber Daya Manusia. Cetakan pertama. ORYZA.

Wibowo. 2010. Manajemen Kinerja. Cetakan ketiga. Jakarta: PT Raja Grafindo.

Zurnali, Cut. 2010. Komitmen Organisasi.id. wikipedia.org/wiki/Komitmen_organisasi. 